\title{
Identificação de áreas suscetíveis a inundação com o auxílio de geotecnologias na Unidade de Negócio Oeste - Sabesp
}

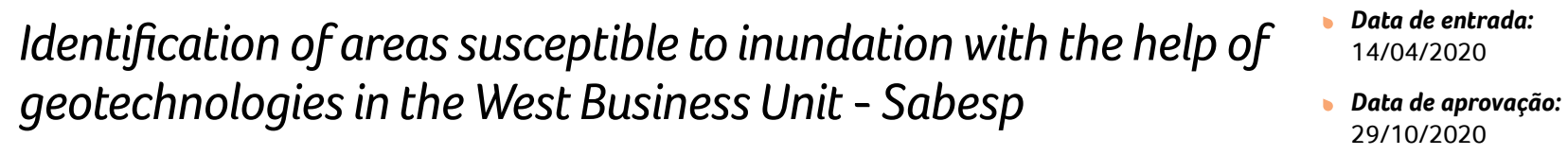

Bruno Pereira Toniolo ${ }^{1 *}$ | Darllan Collins da Cunha e Silva ${ }^{1}$ Katia Sakihama Ventura ${ }^{2}$ | Roberto Wagner Lourenço'

DOI: https://doi.org/10.36659/dae.2022.028

ORCID ID

Toniolo BP (D) https://orcid.org/0000-0002-6602-0181

Silva DCC (iD https://orcid.org/0000-0003-3280-0478
Ventura KS (iD https://orcid.org/0000-0003-3853-668X Lourenço RW (D) https://orcid.org/0000-0002-5234-8944

\section{Resumo}

As enchentes, inundações e erosões urbanas são problemas advindos do impacto da antropização, que podem resultar de ocupações irregulares e ausência planejamento territorial, prejudicando a comunidade, em especial nas áreas com topografia acidentada e várzeas com jusante de aluvião. Nessas regiões, as inundações prejudicam a mobilidade dos moradores e colocam em risco sua integridade física. $O$ principal objetivo deste estudo foi elaborar um mapa de risco à inundação na Unidade de Negócio Oeste (MO) da Companhia de Saneamento Básico do Estado de São Paulo (Sabesp), pelo uso do software livre QGIS. A metodologia utilizou a técnica Analitycal Hiearchy Process (AHP), baseando-se nos seguintes critérios: pedologia, geologia, uso e ocupação da terra, altimetria e declividade do terreno. Foram elaborados mapas para cada critério, respeitando-se as notas de influência dos intervalos e os pesos estatísticos a partir da análise hierárquica. A partir da álgebra de mapas no Sistema de Informações Geográficas (SIG), obteve-se como resultado o mapa final de riscos a áreas de alague. A MO obteve a predominância de risco regular com 52,5\% referente a uma área de 53 mil hectares, sendo que o risco de maior valor observado teve um percentual de 13,6\%. A disposição geométrica das zonas de risco ficou condizente com as áreas da realidade, como por exemplo o bairro do Rochdale, em Osasco, e os vetores dos córregos inundáveis. A metodologia proposta pode ser utilizada como instrumento de suporte para elaboração de projetos ambientais e planeamento urbano que objetivem controlar as inundações e alertar aos moradores que residem nessas áreas.

Palavras-chave: Enchente. Risco. Geotecnologias. AHP.

\section{Abstract}

Inundations, floods and urban erosions are problems arising from the impact of anthropization, which can result from irregular occupations and absence of territorial planning, damaging the community, especially in areas with rugged topography and floodplains downstream. In these regions, flooding impairs the mobility of residents and puts their physical integrity at risk. This paper aims to map the areas susceptible to flooding in the Basic Sanitation

\footnotetext{
1 Universidade Estadual Paulista - Sorocaba - São Paulo - Brasil.

2 Universidade Federal de São Carlos - São Carlos - São Paulo - Brasil.

*Autor correspondente: btonioloasabesp.com.br.
} 
Company of the State of São Paulo (Sabesp), in the Western Business Unit (MO) for the use of the free software QGIS. The methodology used the Analitycal Hiearchy Process (AHP), based on the following criteria: pedology, geology, land use and occupation, altimetry and slope of the terrain. A map was created for each criterion, respecting the influence notes of the intervals and statistical weights from the hierarchical analysis. From the band algebra in the Geographic Information System (GIS), the final map of risks to flood areas was obtained. MO had a predominance of regular risk with $52.5 \%$ referring to an area of 53 thousand hectares, and the highest risk was $13.6 \%$. The geometric arrangement of risk areas was consistent with areas of reality such as the Rochdale neighborhood in Osasco and the vectors of flooded streams. It is hoped that this methodology will be a requirement for the elaboration of environmental projects and urban planning that aim to control the floods and alert the residents of the area of risk. Keywords: Flood. Risk. Geotechnologies. AHP.

\section{INTRODUÇÃO}

Ao longo da história, o início da ocupação das cidades às margens dos córregos e rios ocorreu pela facilidade de transporte do esgoto sanitário e lançamento de resíduos sólidos e pela necessidade de solo fértil para subsidiar a agricultura, pecuária e edificações em geral. Esse cenário favoreceu a consolidação das primeiras metrópoles de maneira imprópria, as quais, em alguns casos, apresentam habitações em áreas ribeirinhas. (SILVA \& MACHADO, 2014).

Essa forma de ocupação é prejudicial à proteção do meio ambiente, por conta dos impactos causados pelas ações antrópicas, os quais refletem diretamente na qualidade e na quantidade de água disponível. Desta forma, em 1965, foi instituída a Lei Federal n 4.771 (Brasil, 1965), que estabelece as Áreas de Preservação Permanente (APPs) para garantir a conservação das margens dos recursos hídricos. Entretanto, as APPs são pouco respeitadas e há monitoramento insuficiente sobre essas regiões, o que interfere na qualidade hídrica, no contexto urbano (SILVA et al., 2017).

Além disso, o crescimento descomedido da rede urbana aumentou a impermeabilização do solo, a supressão da vegetação e o assoreamento de rios, bem como gerou o aumento do volume e da vazão do escoamento superficial, facilitando a ocorrência das inundações e alagamentos (CÔRREA et al, 2015).

As enchentes ocorrem quando uma precipitação intensa acontece e o total de água que chega, concomitantemente, ao rio é maior do que sua capacidade de drenagem, resultando em inundações das áreas de várzea. A execução de infraestrutura para contenção ou minimização de enchentes passou por revisão de projetos urbanos e, ao longo da história, foram adotadas medidas não estruturantes, em conjunto com a realização de obras e o incentivo ao planejamento urbano integrado às demandas sociais, para minimizar os riscos inerentes ao processo (VAZ FILHO et al., 2018).

A falta de inundações facilita a ocupação das áreas de risco pela população, e o mapeamento digital é uma das técnicas que podem auxiliar na prevenção de desastres ambientais, ajudando na tomada de decisão do gestor público (BROLLO et al., 2013). Quanto maior a altimetria, menor a chance de alagamento na região por causa da ação da lei da gravidade, que encaminha a água do escoamento superficial para regiões mais baixas (SIMAS, 2017).

O geoprocessamento ajuda no planejamento ambiental, fornecendo importantes informações 
sobre o meio físico, biótico e antrópico, além de proporcionar auxílio na elaboração de modelos de gestão, cuja finalidade é o monitoramento e mitigação de impactos ambientais (SIMONETTI et al., 2019).

O Sistema de Informações Geográficas (SIG) auxilia no planejamento de áreas ao gerar mapas com dados espaciais, como relevo, cobertura verde, uso e ocupação da terra, área de risco etc., proporcionando grande potencial para tomadas de decisões por parte do gestor ambiental, já que sua finalidade é monitorar e diminuir os impactos do meio ambiente.

Vários estudos utilizaram o SIG para mapear áreas susceptíveis a inundações como os de MagaIhães et al. (2012) que compararam dois métodos distintos no município de Guaçuí (ES) - um por coleta de dados em campo e outro por aplicação do método Analitycal Hiearchy Process (AHP) usando as variáveis de tipo de solo, uso da terra, altitude e declividade; ZANIN et al. (2016), que identificaram áreas de risco de alagamento numa sub-bacia hidrográfica do Rio Jaguari (RS) propondo ações mitigadoras conforme o mapa gerado; e Simas (2017), que fez um estudo das ocorrências históricas de inundações na bacia hidrográfica do córrego Aricanduva no município de São Paulo (SP).

Ventura (2009) esclarece que, entre os métodos multicriteriais, está o método AHP, que exige avaliação subjetiva e experiência profissional do gestor para que a tomada de decisão seja assertiva. Além disso, a autora comenta que diferentes pesos para os critérios considerados podem contribuir para distintos resultados.

O método AHP baseia-se em criar uma escala de prioridade entre os fatores analisados e depois colocá-los numa matriz de relacionamento para fazer uma comparação pareada, havendo então uma interpretação de que existe uma ordem de importância entre os agentes de influência. 0 método AHP determina, por meio da ponderação dos valores desses fatores, uma mensuração global para cada alternativa que será priorizada em forma de matriz de decisão (SAATY, 1991).

Diante do exposto, o objetivo principal desta pesquisa foi elaborar um mapa de risco à inundação com o auxílio de técnicas de geoprocessamento em conjunto com o método multicriterial AHP, aplicados na MO da Sabesp.

\section{MATERIAIS E MÉTODOS}

\section{1 Área de estudo}

A área de estudo corresponde à MO e está localizada na zona oeste da Região Metropolitana de São Paulo (RMSP) (Fig. 1). Trata-se de uma das 16 Unidades de Negócio da Sabesp que integra a Diretoria Metropolitana, respondendo pela operação dos serviços de saneamento básico dos municípios de Barueri, Santana de Parnaíba, Pirapora do Bom Jesus, Cotia, Vargem Grande Paulista, Itapevi, Carapicuíba, Jandira, Osasco, Taboão da Serra e parte de São Paulo (bairros do Morumbi, Jaguaré, Campo Limpo, Pirajussara e Butantã).

Essa unidade foi criada em 1996 e possui uma área de $1035,84 \mathrm{~km}^{2}$. Atualmente atende a uma população de 3,5 milhões de clientes na distribuição de água e na coleta de esgotos, caracterizada por um sistema composto por 11,7 mil km de redes de distribuição e ramais de água, 7,1 mil km de rede de coleta e ramais de esgoto, cerca de 916 mil ligações de água e 611 mil ligações de esgotos (SABESP, 2020). 


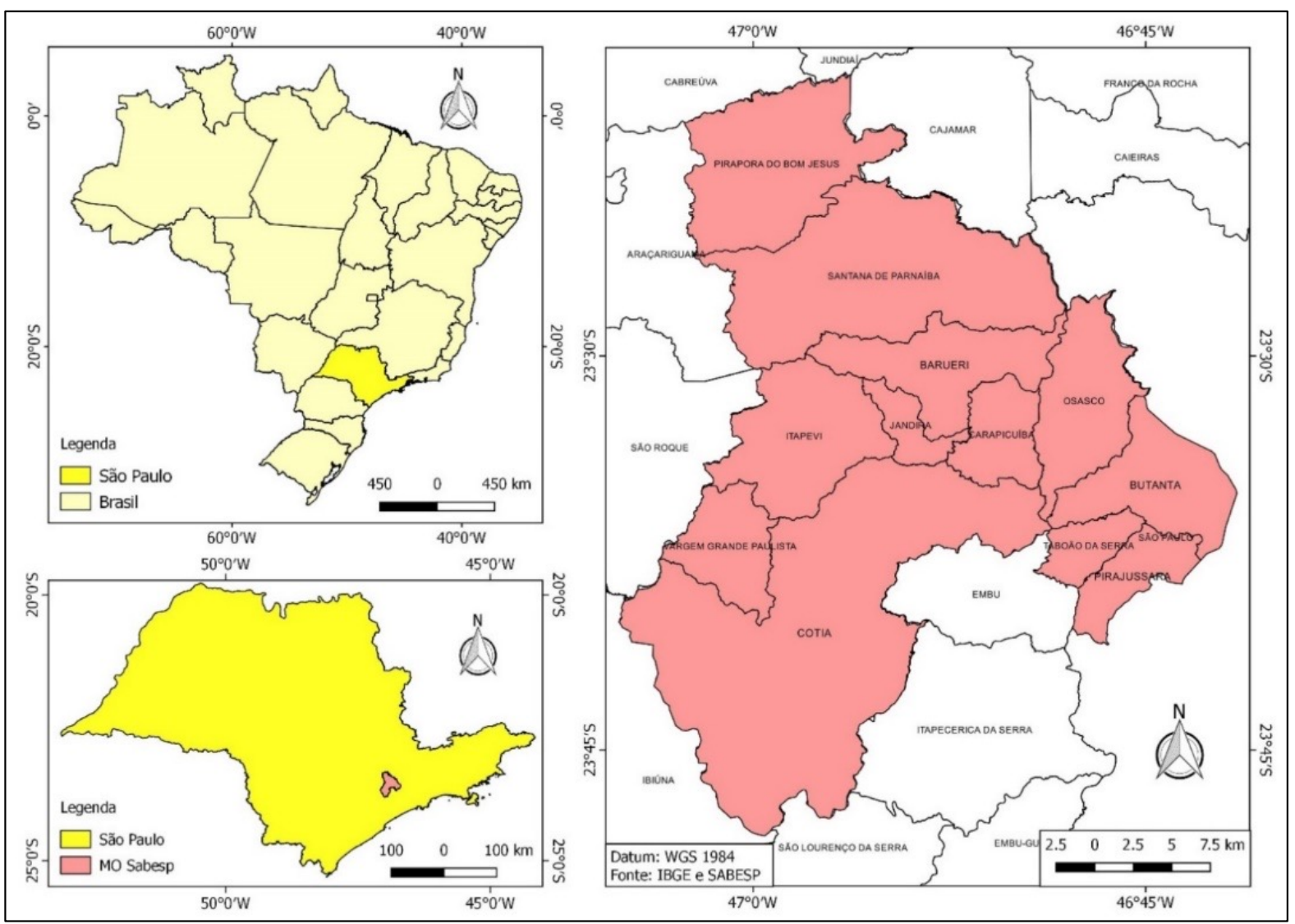

Figura 1 - Localização da Unidade de Negócio Oeste MO da Sabesp (a), situada no Estado de São Paulo (b), Brasil (c). Fonte: Autoria própria

\subsection{Material}

Foram usados para a realização do estudo o software QGIS 2.18 Las Palmas; o modelo digital de elevação (MDE) TopoData do Instituto Nacional de Pesquisas Espaciais (INPE) com resolução espacial de 30m; imagem raster LandSat 8, órbita 219/076 de 27 de Agosto de 2017, horário central 13:04h (UTC); arquivos vetorais (shapefile) de a) pedologia (tipo de solo) e b) textura do solo obtidas do Serviço Geológico do Brasil (CPRM, 2018), e c) córregos inundáveis (BROLLO et al., 2013). O sistema de coordenadas aplicado foi o SIRGAS $2000 \mathrm{com}$ a projeção cartográfica Universal Transversa Mercator (UTM) no fuso 23S.

\subsection{Métodos}

O método AHP, proposto por Saaty (1991), foi utilizado para a classificação e a comparação pareada objetivando representar de forma mais real as condições geomorfológicas da MO, considerando a declividade, a altitude, o uso da terra, a pedologia e a textura do solo como fatores de influência das condições geomorfológicas. Para criar a matriz de decisão, usa-se a escala fundamental de Saaty (1991), conforme apresentado na Tabela 1, a qual é linearmente hiearárquica de importância entre os cinco fatores. 
Tabela 1 - Escala de comparadores AHP.

\begin{tabular}{|c|c|c|}
\hline Valores & Definição & As duas atividades contribuem igualmente para o \\
objetivo.
\end{tabular}

Para a elaboração da base cartográfica que representa os cinco fatores que afetam as condições geomorfológicas, foi necessário classificar em subfatores (intervalos) as variáveis por meio do comando GRASS R.RECODE do QGis 2.18 Las Palmas, sobre as quais foram aplicados valores de acordo com o nível de vulnerabilidade à inundação variando de 0 a 10. Ressalta-se que a atribuição das notas aos intervalos das variáveis foi obtida a partir da média aritmética da análise de quatro especialistas, funcionários da Sabesp, com formações distintas (engenheiro civil, geógrafo, geólogo e biólogo).

Para obter as atitudes de cada ponto, o MDE Topodata foi recortado pelo limite da $\mathrm{MO}$ e posteriormente foi convertido para MDE-Fill para eliminar as depressões espúrias do relevo. 0 mapa de Hipsometria foi reclassificado em seis níveis, baseado numa proporção numérica adaptada de MAGALHÃES et al. (2012).

Tabela 2 - Atribuição de notas ao critério de altitude.

\begin{tabular}{|c|c|}
\hline Hipsometria $(\mathbf{m})$ & Nota \\
\hline $643-736$ & 10 \\
\hline $736-829$ & 9 \\
\hline $829-922$ & 8 \\
\hline $922-1015$ & 7 \\
\hline $1015-1108$ & 4 \\
\hline $1108-1201$ & 2 \\
\hline
\end{tabular}

Fonte: Adaptado de Magalhães et al. (2012).
A inclinação do terreno influencia de forma direta o depósito de água superficial. Áreas planas e de várzea mostram maiores possibilidades de sofrerem inundação do que áreas mais íngrimes. 0 mapa de declividade é derivado do MDE-Fill, sendo gerado a partir do comando GRASS R.SLOPE. O mesmo foi classificado conforme a Tabela 3 referenciado a partir dos níveis da Empresa Brasileira de Pesquisa Agropecuária (EMBRAPA, 1979).

Tabela 3 - Atribuição de notas ao critério de declividade.

\begin{tabular}{|c|c|}
\hline Declividade (\%) & Nota \\
\hline 0 a 3 - Plano & 10 \\
\hline 3 a 8 - Suavemente ondulado & 9 \\
\hline 8 a 20 - Ondulado & 5 \\
\hline 20 a 45 - Fortemente Ondulado & 3 \\
\hline 45 a 75 -- Montanhoso & 2 \\
\hline Maior que 75 - Escarpado & 1 \\
\hline
\end{tabular}

Fonte: Embrapa (1979).

O tipo de solo na região reflete também na habilidade de infitração e escoamento superficial da água. No entanto, para a MO, a divisão é pequena, contendo apenas dois tipos, conforme visto na Tabela 4.

Tabela 4 - Atribuição de notas ao critério de tipo de solo.

\begin{tabular}{|c|c|}
\hline Pedologia & Nota \\
\hline Argissolo Vermelho-Amarelo & 5 \\
\hline Cambissolo Háplico & 3 \\
\hline
\end{tabular}

Fonte: Embrapa (2001). 
A forma da ocupação do solo influencia na intensidade de escoamento e morosidade da infiltração da água. Quanto mais impermeabilizado o solo, mais a água tende a se acumular, aumentando o fluxo da velocidade em comparação com solos revestidos de cobertura vegetal. $O$ mapa de uso e ocupação da terra foi desenvolvido a partir da classificação supervisonada da imagem Landsat 8, usando composição falsa cor RGB765 e o plugin do SCP do QGIS, com resolução espacial de 30 metros. As imagens sofreram correção atmosférica DOS1 e fusão com a banda pancromática para melhorar a resolução espacial (15 metros), sendo reclassificadas em 5, conforme a Tabela 5 .

Tabela 5 - Atribuição de notas ao critério de ocupação da terra.

\begin{tabular}{|c|c|}
\hline Uso e Ocupação do Solo & Nota \\
\hline Hidrografia & 10 \\
\hline Área Urbana / Industrial & 8 \\
\hline Solo Exposto / Campo & 7 \\
\hline Vegetação Arbustiva & 5 \\
\hline Vegetação Arbórea & 3 \\
\hline
\end{tabular}

Fonte: Autoria própria.

Embora se refira ao estudo das rochas e minérios compostos no solo, neste estudo foi considerada a textura do terreno natural, baseando-se na permeabilidade do terreno natural como argila, silte, areia e suas combinações, sendo reclassificado em cinco classes, conforme a Tabela 6.

Tabela 6 - Atribuição de notas ao critério de textura do solo.

\begin{tabular}{|c|c|}
\hline Textura do solo & Nota \\
\hline Predominantemente Argiloso & 9 \\
\hline Predominantemente Argiloso-Siltoso & 7 \\
\hline Predominantemente Argiloso-Síltico-Arenoso & 5 \\
\hline Variável de arenoso a Argilo-Siltoso & 3 \\
\hline Não se aplica & 1 \\
\hline
\end{tabular}

Fonte: CPRM (2019).
Após selecionada cada nota para cada fator foi utilizada a matriz de comparação par a par para determinação dos pesos. Após a determinação dos pesos, cada camada matricial foi cruzada por álgebra de mapa, por meio da Calculadora Raster do QGIS, usando seu respectivo peso estatístico para obter o Mapa de Risco à Inundação. Posteriormente, foram calculadas as áreas de cada região suscetível a inundação por meio do comando GRASS R.REPORT.

Depois foi computado o Índice de Consistência (IC), por meio do auto valor máximo $\left(\lambda_{\max }\right)$ e do número de variáveis analisadas, aqui $n=5$, pela Eq. 1. Conforme Saaty (1991), o IC precisa ser menor que $10 \%(0,1)$; do contrário, precisa-se refazer as ponderações de pesos até que se atinja esse valor.

$\mathrm{IC}=\left(\lambda_{\max }-1\right) /(\mathrm{n}-1)$

Conforme Saaty (1991), o auto valor máximo $\left(\lambda_{\max }\right)$ pode ser calculado pela multiplicação da matriz de comparação $(A)$ pela matriz de pesos normalizados (p), dividindo-se o resultado adquirido (Ap) pelo vetor de pesos normalizados, como é mostrado na Eq.2. O autor supracitado também recomenda o cálculo da Razão de Consistência (RC), que é a divisão do IC pelo Índice Randômico (IR) tabulado (Tabela 7) para a quantidade de variáveis usadas ( $n$ ), sendo que o RC também deve ser menor que 0,1. Assim, o IC e o RC foram aplicados na modelagem.

$\lambda_{\text {max }}=$ média dos valores da matriz resultante de $\mathrm{Ap} / \mathrm{p}$

\section{Tabela 7 - Índice Randômico em função das variáveis} usadas (n).

\begin{tabular}{|c|c|c|c|c|c|c|c|c|c|c|}
\hline $\mathbf{n}$ & $\mathbf{2}$ & $\mathbf{3}$ & $\mathbf{4}$ & $\mathbf{5}$ & $\mathbf{6}$ & $\mathbf{7}$ & $\mathbf{8}$ & $\mathbf{9}$ & $\mathbf{1 0}$ & $\mathbf{1 1}$ \\
\hline IC & 0 & 0,58 & 0,9 & 1,12 & 1,24 & 1,32 & 1,41 & 1,41 & 1,49 & 1,51 \\
\hline \multicolumn{10}{c|}{ Fonte: Autoria própria. }
\end{tabular}




\section{RESULTADOS E DISCUSSÃO}

A Fig. 2 apresenta os mapas das variáveis utilizadas para a elaboração do mapa de risco à inundação.

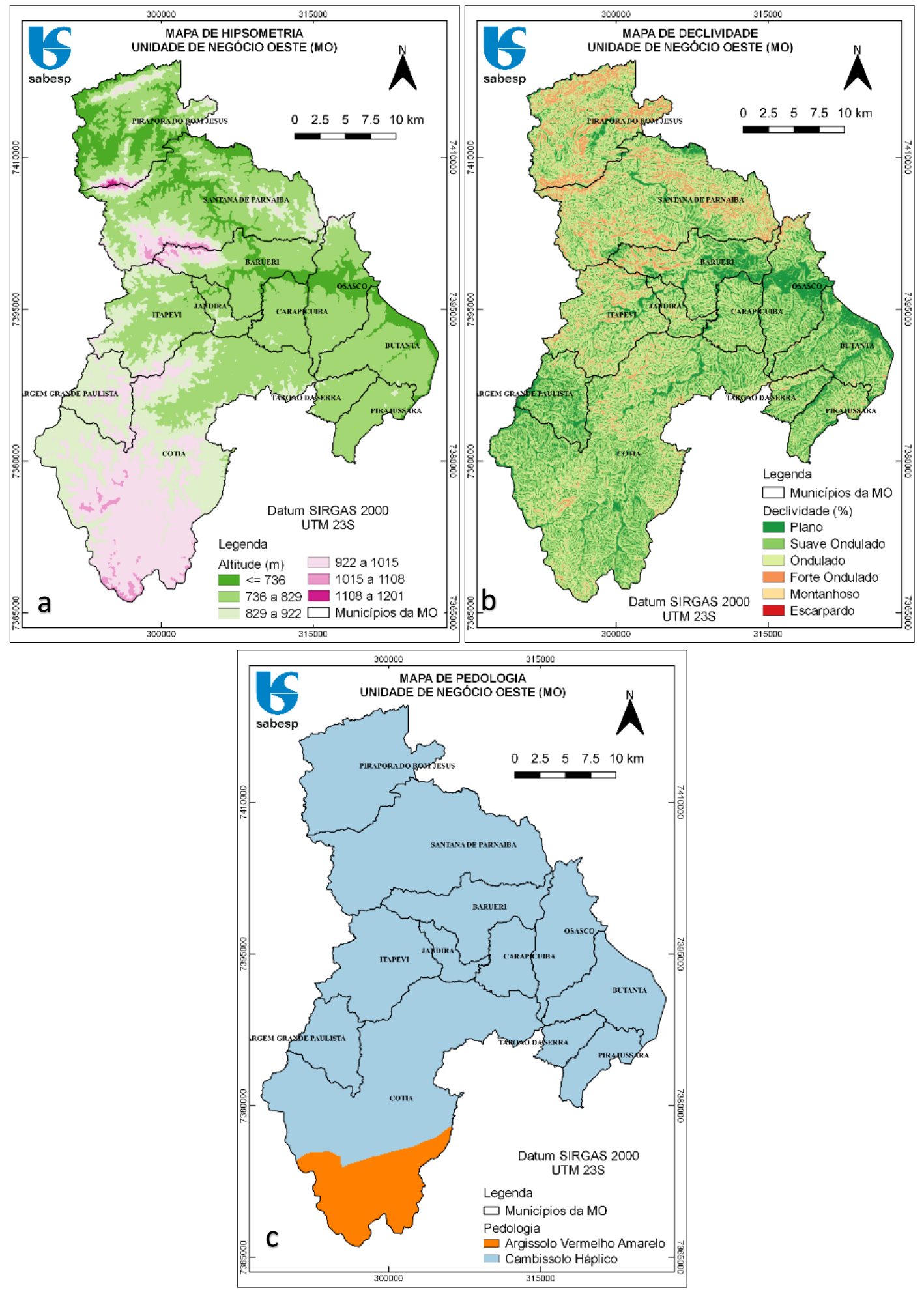




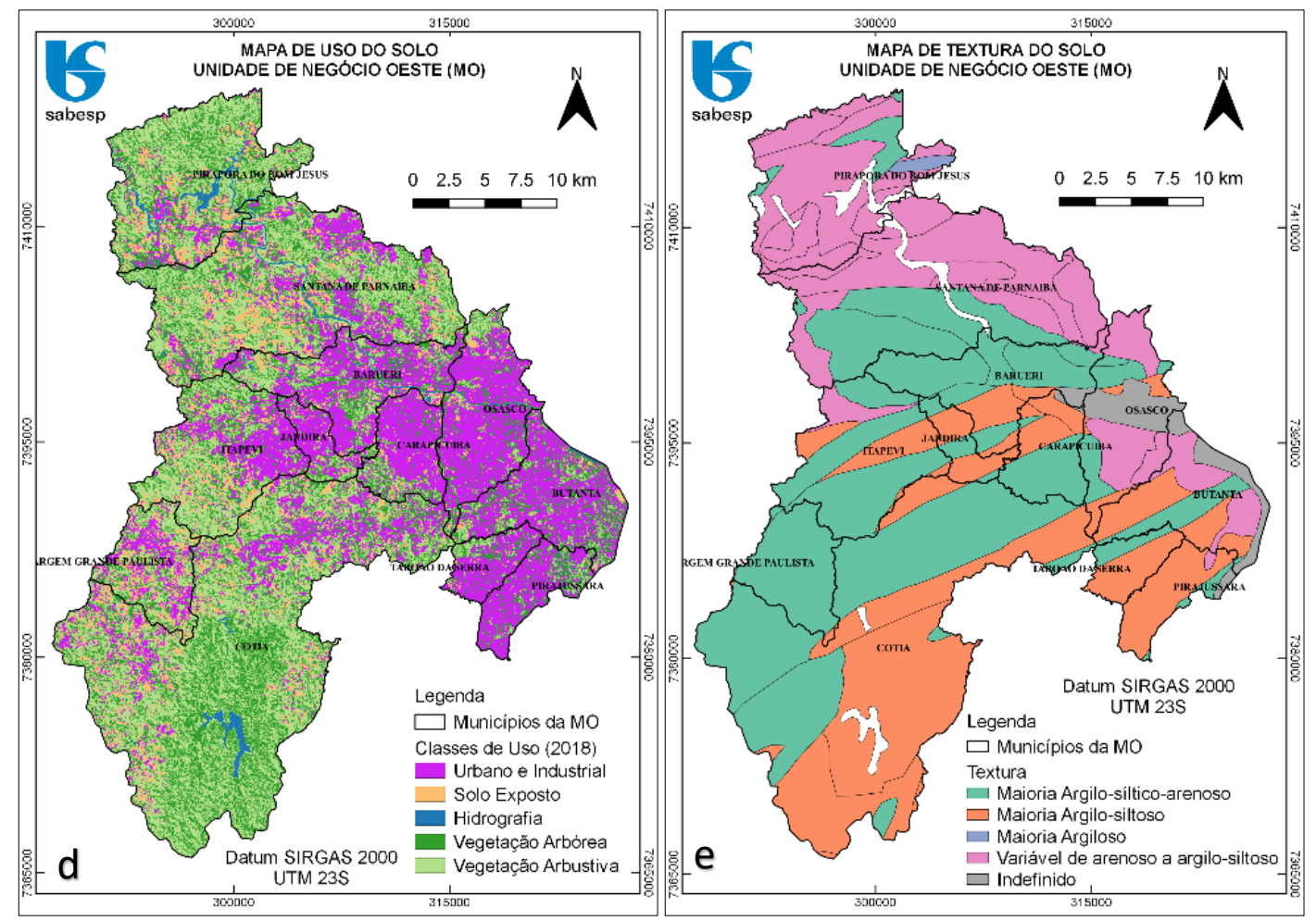

Figura 2 - Mapas dos cinco fatores utilizados na elaboração para análise do risco à inundação: hipsometria (a), declividade (b), pedologia (c), uso da terra (d) e textura do solo (e). Fonte: Autoria própria.

Referente à inclinação do terreno (Fig. 2b), a MO possui uma declividade média de 16,17\%, mínima de $0 \%$ e máxima de $110 \%$, caracterizada pelas áreas com os seguintes relevos: plano com $5.949,12$ ha $(5,8 \%)$; suave ondulado com $20.495,36$ ha (20\%); ondulado com $52.003,32$ ha $(50,7 \%)$; forte ondulado com 22.884,09 ha (22,3\%) e montanhoso com apenas $1.159,18$ ha $(1,13 \%)$. As margens dos rios possuem relevo suave geralmente, e em direção às laterais das sub-bacias a declividade aumenta (vertentes), sendo que as regiões com relevo plano facilitam a infiltração da água no solo e dificultam o escoamento superficial gerando baixa carga de erosão laminar; porém, quando o relevo é inclinado, ocorre o efeito contrário, promovendo o processo erosivo como sulcos, ravinas e voçorocas no solo.

O atual uso e ocupação do solo da MO (Fig. 2d) é diversificado, mostrando regiões naturais e antrópicas, sendo identificados os seguintes usos principais: espelhos de água e hidrografia com $1.556,55$ ha $(1,51 \%$ em relação à area da MO); vegetação arbórea, remanescente de Mata Atlântica dos tipos Floresta Ombrófila Densa Montana e Vegetação Secundária Inicial, com 36.126,63 ha (34,88\%); vegetação arbustiva, pastagem e campos com 26.432,12 ha (25,52\%); solo exposto e regiões degradadas com $9.654,19$ ha $(9,32 \%)$ e área urbanizada de $29.795,78$ ha $(28,77 \%)$.

As áreas de vegetação arbórea possuem alta densidade, que protege o solo contra os efeitos da água pluvial, diminuindo a velocidade do escoamento superficial. As pastagens possuem cobertura vegetal mais rala, a predominar gramíneas e arbustos, tendo risco de erosão maior que as matas. As regiões com solo exposto e áreas edificadas são as mais vulneráveis aos processos 
erosivos devido à impermeabilização e compactação do solo (SILVA; MACHADO, 2014).

As classes de solo (Fig. 2e) ficaram divididas em Cambissolo Háplico, abrangendo 95.143,00 ha $(91,87 \%$ da MO), e em Latossolo Vermelho Amarelo, com $8.417,00$ ha $(8,13 \%)$, correspondentes respectivamente às fragilidades moderada e forte. Segundo CPRM (2018), o fator K do primeiro solo é 0,093756 t.h/MJ.mm, e o do segundo é de 0,006372 t.h/MJ.mm, delineando que quanto maior o valor da erodibilidade, maior a vulnerabilidade a processos erosivos, conforme trabalho semelhante de Magalhães et al. (2012) sobre estimativa de perda de solo na Bacia Hidrográfica do Rio Vieira em Montes Claros, Minas Gerais.

A MO possui um histórico de ocorrências de inundações em que alguns fatores influenciaram nas mesmas, tais como: assentamentos latifundiários irregulares, poluição de corpos hídricos, entupimento de dispositivos de drenagem como bocas de lobo, poços de visita e até mesmo galerias pluviais, além do principal, que é impermeabilização do solo e expansão da malha urbana (TONIOLO et al., 2020).

A Tabela 8 mostra a matriz de comparação pareada das variáveis utilizadas para elaboração do mapa de risco a inundação.

Tabela 8 - Matriz de comparação pareada.

\begin{tabular}{|c|c|c|c|c|c|}
\hline Fatores & Textura & Pedologia & Uso do Solo & Hipsometria & $1 / 5$ \\
\hline Textura & 1 & $1 / 2$ & $1 / 4$ & $1 / 7$ \\
\hline Pedologia & 2 & 1 & $1 / 2$ & $1 / 4$ \\
\hline Uso do Solo & 4 & 2 & 1 & $1 / 2$ \\
\hline Hipsometria & 5 & 4 & 2 & $1 / 4$ \\
\hline Declividade & 7 & 5 & 4 & $1 / 2$ \\
\hline Soma & 19 & 12,50 & 7,75 & 3,95 \\
\hline
\end{tabular}

Fonte: Autoria própria.

Na Tabela 9 é apresentado o peso de cada varável obtida por meio da comparação pareada pelo método da AHP.

Tabela 9 - Determinação de pesos.

\begin{tabular}{|c|c|c|c|c|c|}
\hline Fatores & Textura & Pedologia & Uso do Solo & Hipsometria \\
\hline Textura & $1 / 19$ & $0,5 / 12,5$ & $0,25 / 7,75$ & $0,2 / 3,95$ \\
\hline Pedologia & $2 / 19$ & $1 / 12,5$ & $0,5 / 7,75$ & $0,25 / 3,95$ \\
\hline Uso do Solo & $4 / 19$ & $2 / 12,5$ & $1 / 7,75$ & $0,5 / 3,95$ \\
\hline Hipsometria & $5 / 19$ & $4 / 12,5$ & $2 / 7,75$ & $1 / 3,95$ \\
\hline Declividade & $7 / 19$ & $5 / 19$ & $4 / 7,75$ & $0,2 / 2,09$ \\
\hline Soma & 19 & 12,50 & 7,75 & $0,5 / 2,09$ \\
\hline
\end{tabular}

Fonte: Autoria própria.

A partir da Tabela 9 obteve-se como resultado a Eq. 3, da qual foi gerado o Mapa de Risco à Inundação (Fig. 3).

$R I=(0,0488 \times T)+(0,0817 \times P)+(0,1491 \times U C S)+(0,2667 \times H)+(0,4537 \times D)$

Sendo: RI é o risco à inundação; T é o valor do pixel para o mapa de textura do solo; $P$ é o valor do pixel para o mapa de pedologia; UCS é o valor do pixel para o mapa de uso e ocupação do solo; H é o valor do pixel para o mapa de hipsometria; D é o valor do pixel par ao mapa de declividade. 
O valor do IC calculado para determinar a integridade dos pesos atribuídos às variáveis do RI pelo método AHP foi de $2,4 \%$, ou seja, abaixo de $10 \%$, logo há consistência nos resultados adquiridos. Em relação ao RC, o valor obtido foi de 1,6\%, também menor que $10 \%$, apontando que os pesos atribuídos apresentam também consistência.

De acordo com Santos el al. (2010), a fase de atribução dos valores, com base na escala de comparadores, é considerada um momento essencial durante o processo de mapeamento de inundação, pois, embora haja certa subjetividade por causa da experiência do analista na escolha das notas, os valores impostos a um fator interferem de forma direta no resultado obtido.

A Fig. 3 apresenta o mapa de risco à inundação com destaque para os rios mais sujeitos a enchentes, conforme a Agência Nacional das Águas (ANA, 2014).

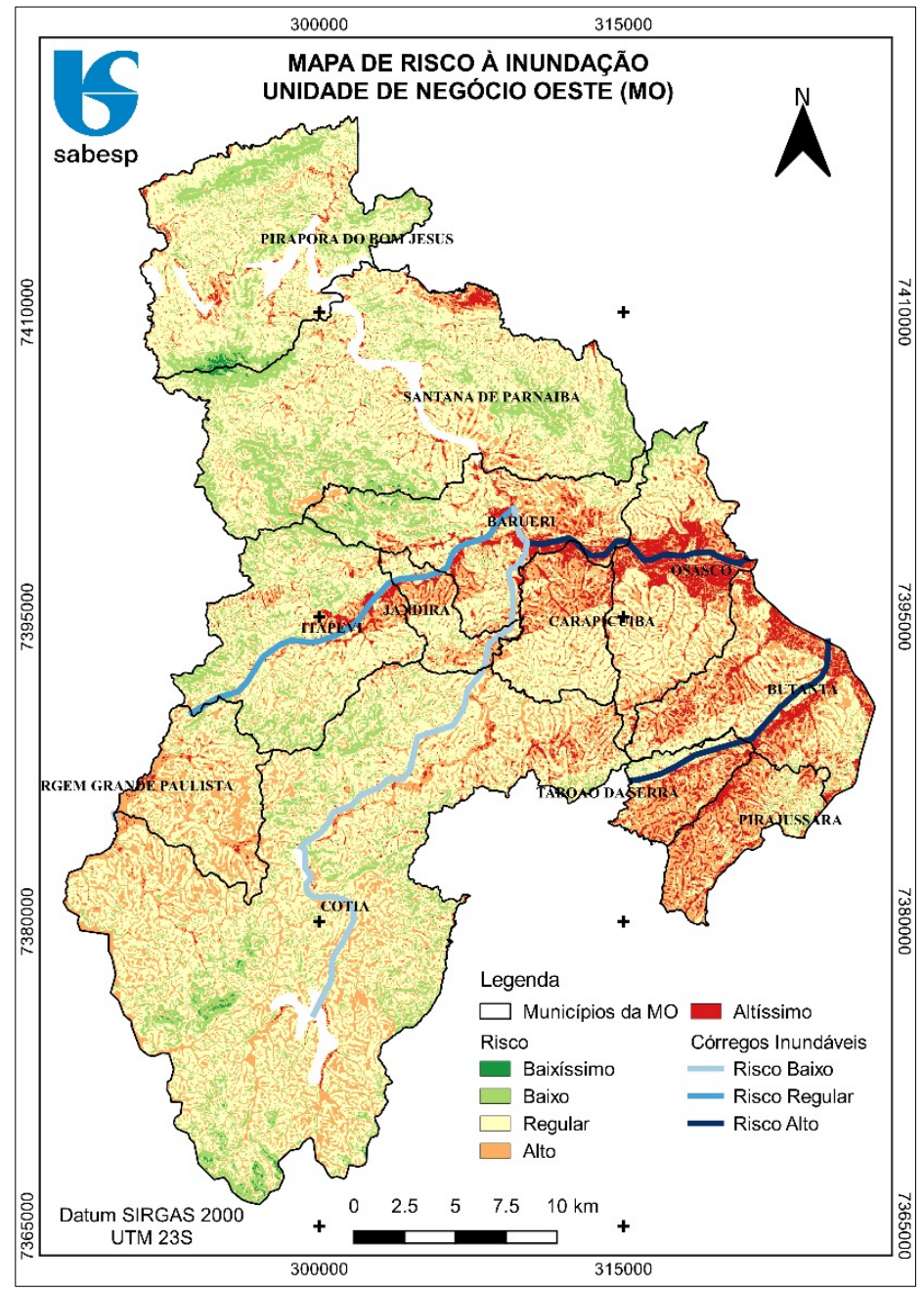

Figura 3 - Mapa de risco à inundação na MO. Fonte: Autoria própria.

Analisando a Fig. 3, observa-se que as áreas urbanas são as que apresentam risco entre alto e altíssimo, especialmente nos municípios de $\mathrm{Ba}$ - rueri, Carapicuíba, Osasco e São Paulo. A mancha vermelha sobreposta com o vetor do córrego inundável do rio Tietê (verde escuro) corrobora 
o fato de que a impermeabilização próxima das áreas ribeirinhas, geralmente planas e de baixa atitude, contribui para o aumento da vulnerabilidade às inundações.

Nota-se que a mancha de risco altíssimo estaciona no distrito de Alphaville em Barueri, na confluência de outros dois córregos, que é justamente o término da aglomeração urbana: dali pra frente, o espaçamento demográfico é menor ao longo do Rio Tietê e Estrada dos Romeiros, com predominância de áreas verdes e solos expostos (empreendimentos imobiliários ainda em implantação).

As áreas com risco de muito alto ao longo do Rio Tietê, localizadas entre os municípios de Osasco e Barueri, possuem altitude de até 735 metros aproximadamente e com declividade menor que $3 \%$. Observa-se que essa classe está situada majoritariamente nas várzeas deste rio, o qual é o principal córrego da $\mathrm{MO}$, recebendo fluxo dos demais córregos.

Nessas áreas se encontram grandes edificações, que bloqueiam a infiltração da água pluvial no solo, assim toda enxurrada vai direto para o Rio Tietê. Embora as várzeas deste rio estejam situadas em argissolo vermelho amarelo, estipulado como moderadamente drenado, nota-se que a impermeabilização do solo aumenta a probabilidade de inundação.

A incidência de áreas de baíxissimo risco foram praticamente desprezíveis com alguns pontos espaçados em Cotia na Reserva do Morro Grande e entre Pirapora do Bom Jesus e Santana do Parnaíba no bairro do Suru, o qual possui relevo montanhoso e uma das maiores altitudes da MO.

Observa-se que muitas áreas de risco entre baíxissimo e regular encontram-se afastadas dos rios inundáveis, corroborando que a distância de um pixel da imagem matricial a um curso d'gua é inversamente proporcional ao risco de inun- dação, isto é, quanto mais próxima uma região está de uma rede de drenagem, maior é a probabilidade de ser inundável. Áreas com risco acima de moderado eventualmente afastadas de rios principais, como por exemplo, a face norte do município de Santana de Parnaíba em relação ao rio Tietê (espaço em branco na Fig. 3), podem ser locais com alta declividade, solo impermeabilizado, rede de drenagem entupida ou deficiência de saneamento.

Com exceção de alguns bairros planejados e de alto padrão, como Alphaville em Santana de Parnaíba e Morumbi em São Paulo, a maioria dos distritos dos municípios contidos na $\mathrm{MO}$ se desenvolveram de forma desordenada. Esses distritos são caracterizados pela alta densidade demográfica e pelo descarte indevido de resíduos sólidos, os quais contribuem no obstrução do sistema de drenagem de águas pluviais e assoreamento dos rios, intensificando alagamentos e inundações, respectivamente (SABESP, 2018).

O risco médio à inundação da $M O$ é classificado como regular ao valor de 6,53 , com desvio padrão de $\pm 1,106$. O município com maior risco é Osasco, classificado como alto, ao valor de 7,11 com desvio padrão de $\pm 1,197$. Já o menor risco é atribuído a Pirapora do Bom Jesus, do tipo regular, ao valor de 5,66 e com desvio padrão de $\pm 1,038$.

O município de Osasco possui esse risco por causa do seu bairro Jardim Rochdale, muito conhecido por sofrer inundações nas épocas de chuva, sendo até mesmo televisionado nos programas locais de jornalismo devido à sua constância de alagamentos. O Rochdale está situado no Braço Morto do Rio Tietê que é um lago pluvial em formado de "U" sendo um meandro de baixa vazão, caracterizado pela existência de assentamentos irregulares (favela), resíduos sólidos e palafitas ao longo de sua margens, além de seu leito estar assoreado em determinados pontos. Há um 
projeto de drenagem por parte da Prefeitura de Osasco que consiste na execução de obras de macrodrenagem, limpeza, desobstrução, e retificação do córrego, além da realocação das famílias situadas em área de risco (PMO, 2015).

A Tabela 10 apresenta de forma quantificada as áreas identificadas para cada zona de risco em hectares e também em porcentagem.

Tabela 10 - Áreas em hectares e porcentagem por zona de risco.

\begin{tabular}{|c|c|c|}
\hline Zona de Risco & Área (ha) & $\%$ \\
\hline Baixíssimo $(2,17$ a 3,63$)$ & 233,28 & 0,23 \\
\hline Baixo $(3,63$ a 5,01$)$ & $16.443,86$ & 16,26 \\
\hline Regular $(5,01$ a 6,54$)$ & $53.066,30$ & 52,48 \\
\hline Alto $(6,54$ a 8,00$)$ & $17.649,32$ & 17,45 \\
\hline Altíssimo $(8,00$ a 9,45) & $13.723,71$ & 13,57 \\
\hline Total & $101.116,47$ & 100 \\
\hline
\end{tabular}

Observa-se que o mapeamento das regiões mais vulneráveis à inundação é mais útil para o planejamento de medidas mitigadoras não estruturais do que a implantação de medidas mitigadoras estruturais, uma vez que enquanto estas compreendem as obras de engenharia (bacias de retenções, retificação e canalização de córregos etc.), as medidas não estruturais priorizam ações que ordenem o território e disciplinem a sociedade e a economia, como por exemplo: atualização/regulamentação de plano diretor, educação ambiental sobre poluição difusa e corpos hídricos, seguro-enchente e sistema de alertas de inundações (SIMAS, 2017).

\section{CONSIDERAÇÕES FINAIS}

O modelo AHP mostrou um mapeamento aceitável para a determinação de vulnerabilidade de inundação, tendo grande versatilidade, a oferecer resultados que seriam inviáveis de outras formas, como visitas de campo a locais remotos de acesso difícil. Assim, o método facilita a estruturação dos problemas e ajuda na tomada de decisões.
Os problemas decorrentes da precipitação urbana podem ser mitigados com obras de drenagem urbana, mas é obrigatório o estudo da área usando técnicas de geoprocessamento, a visar a delimitação da área de risco. Esse procedimento resulta na criação de um artifício fundamental na ajuda à gestão pública para depois adotar medidas precisas no controle dos riscos existentes de inundações e solapamentos.

A espacialização dos planos de informação em SIG facilita a intepretação dos resultados, em especial a sobreposição de mapas como auxílio na tomada de decisões ambientais. Contudo ressalta-se que as técnicas de geoprocessamento possuem limitações e devem ser escolhidas com cautela para cada finalidade.

Recomenda-se que as informações obtidas neste estudo sirvam como orientadores pelos gestores públicos na elaboração de projetos de saneamento, projetos ambientais e planejamento territorial, melhorando a qualidade documental e a análise de medidas mitigadoras ambientais. Também se recomenda que sejam feitos novos mapeamentos de áreas vulneráveis a inundações em parceria com a prefeitura dos municípios como forma de sinalizar e alertar as comunidades situadas em áreas de riscos.

\section{AGRADECIMENTOS}

Os autores gostariam de agradecer aos técnicos da Sabesp pelo fornecimento das informações e pelo empréstimo da viatura para visitas de campo, em especial aos funcionários da Divisão de Cadastro Técnico Oeste (MOED) e ao Departamento de Engenharia (MOE).

\section{CONTRIBUIÇÃO DOS AUTORES}

Todos os autores contribuíram de forma igualitária. 


\section{REFERÊNCIAS}

ANA - Agência Nacional das Águas. Mapa de Vulnerabilidade à Inundação do Estado de São Paulo. 2014. Disponível em < https://metadados.ana.gov.br/geonetwork/srv/pt/metadata.show?uuid $=e 44 b 4 d b c-e 43 c-4109-a 1 b 2-709732424 a 4 d>$. Acesso em 10 out. 2019.

BRASIL. Lei n $^{\circ} \mathbf{4 . 7 7 5}$, de 15 de setembro de 1965 . Institui o novo Código Florestal. Disponível em: http://www.planalto.gov.br/ccivil_03/leis/L4771.htm. Acesso em: 19 jan. 2019.

BROLLO, M.J.; TOMINAGA, L.K.; GUEDES, A.C.M. Texto Diagnóstico do Solo: Desastres Naturais. Meio Ambiente Paulista: Relatório de Qualidade Ambiental 2013. Organização: Edgar Cesar de Barros. São Paulo: SMA/CPLA, 2013. 215p. ISBN 978-85-8156011-3.

CORRÊA, E. A.; MORAES, I. C.; PINTO, S. A. F. Estimativa da Erodibilidade Tolerância de Perdas de Solo na Região do Centro Leste Paulista. Geociências (São Paulo), v. 34, n. 4, p. 848-860, 2015. Disponível em: <www.revistageo ciencias.com.br/34/volume34_4_files/34-4-artigo-08.pdf\%0A>. Acesso em: 01 set. 2020.

CPRM. SERVIÇO GEOLÓGICO DO BRASIL. Unidades Litoestratigráficas - Mapa Estadual de São Paulo. GeoSGB - Visualizador de mapas GIS. CPRM, 2018. Disponível em < http://geowebapp. cprm.gov.br/ViewerWEB/>. Acesso em 10 fev. 2020.

EMBRAPA. EMPRESA BRASILEIRA DE PESQQUISA AGROPECUÁRIA. Serviço Nacional de Levantamento e Conservação de Solos (Rio de Janeiro, RJ). Súmula da 10. Reunião Técnica de Levantamento de Solos. Rio de Janeiro: 1979. 83p. (Embrapa-SNLCS. Miscelânea, 1).

MAGALHÃES, I.A.L.; NERY, C.V.M.; ZANETTI, S.S.; PENA, F.E.R.; AVELINO, R .C.; SANTOS, A.R. Uso de Geotecnologias para Estimativa de Perda de Solo e Identificação das Áreas Susceptíveis a Erosão Laminar na Sub-Bacia Hidrográfica do Rio Vieira, Município de Montes Claros, MG. Cadernos de Geociências, v. 9, n.2, 2012.

PMO - Prefeitura do Município de Osasco. Plano Municipal de Saneamento Básico de Osasco. Plano Municipal de Drenagem e Manejo de Águas Pluviais. Osasco, 2015.

SAATY, T. L. Método de Análise Hierárquica. São Paulo: McGraw-Hill Publisher, 1991.

SABESP. COMPANHIA DE SANEAMENTO BÁSICO DO ESTADO DE SÃO PAULO. Quem Somos Nós - Conheça a MO. Portal Corporativo [intranet], 2018.

SANTOS, A. R.; LOUZADA, F. L. R O.; EUGENIO, F. C. (Coord.). ArcGIS 9.3 total: aplicações para dados especiais. Alegre, ES: Ciências
Agrárias Universidade Federal do Espírito Santo/CAUFES, 180 p., 2010.

SILVA, D. C. C.; ALBUQUUERQUE FILHO, J. L.; OVEIRA, R. A. ; LOURENÇO, R. W. Methodology for potential degradation analysis of water resources in watershed. Caderno de Geografia, v. 27, p. 455-466, 2017. https://doi.org/10.5752/p.2318-2962.2017v27n50p455.

SILVA, V. C. B.; MACHADO, P. S. SIG na Análise Ambiental: Susceptibilidade Erosiva da Bacia Hidrográfica do Córrego Mutuca, Nova Lima - Minas Gerais. Revista de Geografia, v. 31, n. 2, 2014.

SIMAS, I. T. H. Análise retrospectiva de episódios de inundações na bacia hidrográfica do rio Aricanduva - São Paulo. Dissertação de Mestrado em Geografia Física, 169 f. Universidade de São Paulo. São Paulo, 2017. https://doi.org/10.11606/D.8.2017.tde21072017-162915.

SIMONETTI, V. C.; FASCARELI, D.; GONTIJO, E. S. J.; MELO, D. S.; FRIESE, K.; SILVA, D. C. C.; ROSA, A. H. Water quality indices as a tool for evaluating water quality and effects of land use in a tropical catchment. International Journal of River Basin Management, v. 17, p. 1-34, 2019. http://dx.doi.org/10.1080/15715124.2019. 1672706

TONIOLO, B. P.; SILVA, D.C.C.; LOURENÇO, R. W. Uso de Geotecnologias para Delimitação de Susceptibilidade Erosiva na Unidade de Negócio Oeste SABESP. Cidades Verdes, São Paulo, v. 8, n. 17, p. 76 - 90, 2020. https://doi.org/10.17271/2317860481720202 309.

VAZ FILHO, P.; VENTURA, K. S.; CAMPOS-CABALLERO, P.; COMIN, E.T. Proposta de Sinalização em Áreas de Risco Sujeitas a Alagamento em Vias Urbanas par ao Município de São Carlos - SP. In: OTTONI, A. B.; ROSIN, J. A. R. G.; FOLONI, F. M (org.). Drenagem Urbana: Soluções Alternativas Sustentáveis, $118 \mathrm{f}$. Editora ANAP. 2018.

VENTURA, K. S. Modelo de avaliação de gerenciamento de resíduos de serviços (RSS) com uso de indicadores de desempenho: estudo - Santa Casa de São Carlos - SP. Tese de Doutorado. Escola de Engenharia de São Carlos, Universidade de São Paulo. São Carlos - SP, 2009. https://doi.org/10.11606/T.18.2009.tde19072009-120104.

ZANIN, V. L.; MELLO, I. S.; PITHAN, P. A. Identificação de Áreas com Risco de Inundação por Meio de Análise Ambiental e Geoprocessamento. In: $12^{\circ}$ Congresso de Cadastro Técnico Multifinalitário e Gestão Territorial, 2016, Santa Catarina. Anais... Santa Catarina, 11 f., 2016. 